Laboratory of Economics and Management

Sant'Anna School of Advanced Studies

Piazza Martiri della Libertà, 33 - 56127 PISA (Italy)

Tel. +39-050-883-343 Fax+39-050-883-344

Email: lem@sssup.it Web Page: http://www.lem.sssup.it/

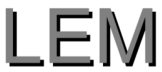

Working Paper Series

\title{
More or Better? Measuring Quality versus Quantity in Food Consumption
}

Corinna Manig ${ }^{\S}$

Alessio Moneta ${ }^{\S}$

$\S$ Max Planck Institute of Economics, Jena, Germany 


\title{
More or Better? Measuring Quality VERSUS QUANTITY IN FOOD CONSUMPTION*
}

\author{
Corinna MANIG ${ }^{1}$ and Alessio MonetA ${ }^{2}$
}

November 13, 2009

\begin{abstract}
As people become richer they get the opportunity of consuming more but also qualitatively better goods. This holds for a basic commodity like food as well. We investigate food consumption in Russia, taking into account both expenditure and nutrition value in terms of calories. We analyze how food consumption patterns change with increasing income by estimating both "quantity Engel curves" and "quality Engel curves." The former describe the functional dependence of calories consumed on total expenditure. The latter trace out the dependence of price per calorie as a proxy for quality on total expenditure. We compare income elasticities of quantity with income elasticities of quality. In these Russian data for years 2000-2002 the reaction of quality to changes in income is significantly stronger than the reaction of quantity to income changes suggesting that Russian households tend to choose higher quality food items as income rises.
\end{abstract}

Keywords: Food consumption patterns, calorie intake, income elasticity decomposition, Engel curves, method of average derivatives.

JEL classification: D12

*We would like to thank Ulrich Witt, Matteo Barigozzi, Andreas Chai, Tommaso Ciarli, Wolfhard Kaus, and Andreas Freytag for discussion, comments, and helpful suggestions.

${ }^{1}$ Corresponding author. Max Planck Institute of Economics, Evolutionary Economics Group, Kahlaische Strasse 10, 07745 Jena, Germany; email: manig@econ.mpg.de

${ }^{2}$ Max Planck Institute of Economics, Evolutionary Economics Group; email: moneta@econ.mpg.de 


\section{Introduction}

The purpose of this paper is to analyze the influence of increasing income on the quality of food consumed in Russia. It is common knowledge that as households become wealthier, their budget share allocated to food is on average decreasing (Engel's law). Empirical research about consumption in transition countries, however, shows that both the level of food expenditure and the quantity consumed in terms of calories increase with growing income (Ivanova, Dimitrov, Ovchariva, Dellava, and Hoffman 2006). Do households consume also qualitatively better food, when they become richer? The issue as to households upgrade the quality of food consumption in response to income has been occasionally addressed in the development economics literature. Subramanian and Deaton (1996) investigate the relationship between economic and nutritional status in rural India. Estimating a parametric model of demand for calories, they are able to disentangle the (income) elasticity of calories from the elasticity of calorie price. They find that these elasticities are approximately the same. This means that Indian rural families upgrade quality in the same manner as quantity when their income increases (for a comprehensive survey on health, nutrition, and economic development, see Strauss and Thomas (1998)). Other studies devoted to this issue are Behrman and Deolalikar (1987) and Boius (1994), who found an income elasticity of calories of almost zero.

The fact that there are only few studies exploring the difference between quality and quantity responses is probably due to the difficulty of gathering adequate data. While the assumption of price as proxy for quality is generally accepted (Bils and Klenow 2001), information about the actual prices is difficult to obtain. To escape this problem, the standard way to obtain prices is to divide expenditures by quantities purchased. However, data sets including quantities are not as frequent as those covering only expenditures.

In this paper, we use data from the Russia Longitudinal Monitoring Survey (RLMS), which have the advantage of comprising expenditures and purchased quantities on detailed food items, as well as individual calorie intake. Our focus is on years 2000, 2001, and 2002. During this period the economic situation has been relatively stable in Russia, accompanied by considerable economic growth rates. According to the World Bank, the growth rate of real GDP in 2001 was 5.2\%. Economy, in terms of real GDP, has grown from 1998 to 2001 by $20 \%$. Real disposable household income has risen during the period $2000-2001$ by $5.9 \%$, and real wages have grown by $19.8 \%$ with an average monthly dollar wage reaching 122 US $\$$. Unemployment rate (ILO definition) reached 9\% at the end of 2001 and inflation was 18.6\% (The World Bank 2002).

Our analysis of food consumption in terms of both quantity and quality growth is going to be relevant for three different research areas. First, our work will add empirical evidence on consumption patterns in Russia, which is a country typically considered in transition economic studies (Shleifer and Teisman 2003).

Second, we offer a new perspective to look at evolutionary theory of consumption. This theory explains consumption activity as driven by basic needs and acquired wants (Witt 2001). 
Among the basic needs, the need for calories has to be satisfied with a relatively high frequency to avoid harmful consequences. This need is, like any other need, subject to satiation. The pace at which it reaches satiation is different from other needs. This path is empirically captured by regressing consumed quantity on income via what we call "quantity Engel curve." However, the changing pattern of expenditure may not be exclusively determined by consumed quantities. Households may tend to buy more expensive goods as their income increases. In this case the quantity Engel curve would not coincide with the "expenditure Engel curve", which traces out how household expenditure (i.e. price $\times$ quantities) depends on income. In this paper we stress the importance of analyzing changes in quality of consumption, i.e. how the unit price of food changes as income increases. This phenomenon is described by "quality Engel curve", a notion first introduced by Bils and Klenow (2001). We argue that by decomposing the income elasticity for expenditure into elasticity for quality and quantity we can respectively analyze the responsiveness of changes in quantity and quality on income changes. The quality Engel curve allows us to evaluate the influence of factors that drive food consumption but are not directly related to the need for calorie intake. For instance, a preference for variety may cause people to buy some more expensive items, when they become richer. Other factors which may stimulate people to afford more expensive items include the desire for a healthy diet and the need for status or social recognition. With the method proposed in this paper, although we are not able to identify each of these single factors, we are able to disentangle calorie intake from all the other factors influencing food expenditure.

Third, we propose to estimate income elasticities without assuming any functional form of the Engel curves. The typical approach to obtain an income elasticity is to derive it from the estimated parameters of a fully specified Engel curve (Subramanian and Deaton 1996, Bils and Klenow 2001). Instead, we apply the method of average derivative developed by Härdle and Stoker (1989) which permits us to estimate the derivative of a regression function without knowing its functional form a priori.

The paper is organized as follows. Section 2 describes the data we use. In section 3 we display how food expenditure shares differ with respect to several household sizes and subcategories of food. Furthermore, we show to which extent the nutritional composition of the diet relates to income. Section 4 presents the econometric method and shows the results of the estimation of both quality and quantity elasticities. Furthermore, three types of Engel curves, namely expenditure, quantity and quality Engel curves are displayed. Section 5 concludes.

\section{Data description}

The data used here are taken from the Russia Longitudinal Monitoring Survey (RLMS) for the years 2000-2002 provided by the Carolina Population Center and Russian Institute of Sociology 11 The RLMS is a longitudinal study of populations of dwelling units, designed to

\footnotetext{
${ }^{1}$ We thank the Russia Longitudinal Monitoring Survey Phase 2, funded by the USAID and NIH (R01HD38700), Higher School of Economics and Pension Fund of Russia, and provided by the Carolina Population Center and Russian Institute of Sociology for making these data available.
} 
provide a repeated cross-section sampling. Data from 1992 onwards have been collected in a household based survey design to study and measure the effect of Russian reforms on wellbeing of households and individuals with primary emphasis on household consumption and individual health. The survey includes observations on more than 4500 households and more than 12000 individuals living in those households.

The RLMS provides both household data and constructed variables. A multitude of information on individual and household level has been collected, among which are socioeconomic variables (e.g. sex, age, employment situation, family composition, educational level of family members), detailed description of expenditures, health status, geographical information, living conditions, housing, and household equipment. Moreover, data have been also recorded on indicators of wealth, such as landownership, house area, and type of construction. Respondents are asked to recall expenditures spent on more than 90 products and services over the last seven days, thirty days, or three months respectively (depending on the good or service under consideration) as well as physical quantities when appropriate. Furthermore, there are 58 food items in the list, including food consumption away from home. For our analysis we used data on socioeconomic variables, geographical variables, expenditure data, and calorie intake per person per day as a constructed variable. We take into account regional effects by distinguishing between urban, rural and PGT areas. The latter are a locality intermediate in character and status between cities and rural localities 2

We use total expenditure as a proxy for permanent income. Income data reported in our data set are probably less informative due to wage arrears and delayed wage payment (Desai and Idson 2000) and misreporting $\cdot^{3}$ Besides problems of data quality, there are also conceptual reasons in favor of using total expenditures instead of income. For instance, total expenditure may be a better indicator for both declared and undeclared resources, especially those referring to low income groups. Consequently, when expenditures are higher than money income (measured or reported), expenditures may be a better indicator for the living standard that the household can reach, even when taking into account formal and informal credit for consumption. Additionally, expenditures may be more stable than income reported at a certain point in time and therefore better reflecting the possible long-term income (see e.g. Hagenaars, de Vos, and Zaidi 1994, Charles, Hurst, and Roussanov 2009). Taking these arguments into account, total expenditure was constructed from the fine level expenditure records. This process involved merging food expenditures (recorded for seven days), expenditure on housing and fuel (recorded for thirty days) and other expenditures (recorded for three months). Total expenditures have been calculated for seven days.

Individual caloric intake as constructed by the RLMS is based on a 24 hours recall. Partic-

\footnotetext{
${ }^{2}$ PGT is a Russian acronym: posyolok gorodskogo tipa, i.e. "urban type settlement". This locality is one of the results of Soviet urban design.

${ }^{3}$ Wage arrears have been a major problem in Russia during the transition process. In October 2003, $20 \%$ of working age individuals were owed back wages (Kazakova 2007). Lehmann, Wadsworth, and Acquisti (1999) consider wage arrears as a kind of firm strategy to deal with negative demand shocks. They find large regional variation in the wage owed, depending on the industrial structure: workers in Moscow are less affected than workers in areas with mainly agricultural industry or large industrial firms. They conclude that the arrears status depends on the firm characteristics, not on individual characteristics.
} 
ipants were asked to report numerous information on food consumption during the previous day, such as time of eating, place of eating (at home or away from home), name of the food item, dish or beverage, type of food intake (breakfast, lunch, or dinner), amount of food intake (in grams) and whether the food was home-cooked or not. Food consumed was converted into nutrients using calorie content and nutrition tables. Afterward, macronutrients and calories were summed up for every household member leading to values of consumption per person per day. This very detailed procedure ensures a low degree of misreporting and a relatively precise measurement of individual food intake per day.

The individual calorie intake was applied to estimate quantity and quality Engel curves and the calculation of the daily macronutrients intake. Engel curves and resulting elasticities have been estimated on the household level. Therefore, we summed up all calorie values reported by household members to obtain the value for the whole household and multiplied the result by seven, leading to an average measurement for the calorie intake per household per week. For that reason, estimation results can be related to actual calorie consumption. In contrast, calorie values for particular food items or categories have been calculated using calorie content and nutrition tables provided by Souci, Fachmann, and Kraut (1989). Accordingly, in these cases we calculated calorie availability rather than calorie intake for single food items or food categories by using information about amount and costs of food items bought. The distinction between calorie consumption and calorie availability might be important if we have reasons to assume a high rate of wastage that would influence the results. We strongly believe that this is not the case for Russian food consumption, simply because the majority of the households cannot afford this kind of behavior.

Of course, there are also a number of limitations. First, data have been collected during several months and consequently seasonal price variance especially for fruits and vegetables cannot be avoided. Second, expenditure data may underrate the effect of stockpiling of foods with long shelf life such as grains, potatoes, canned foods, and highly processed foods. Finally, we face the problem of misreported data, for example for alcohol consumption or food consumption in general.

\section{Expenditure shares and nutritional composition}

Table 1 shows food budget shares for different household sizes for the years 2000, 2001, and 2002. Expenditure shares are declining from 2000 to 2002 for each household size considered, as well as for the aggregate. However, food shares are rather high, with percentages ranging in 2000 from $50.9 \%$ for a 4-person household to $63.6 \%$ for a single-person household, in 2001 from $48.3 \%$ for a 3-person household to $60.1 \%$ for a single person household, and in 2002 from $45.3 \%$ for a household with four members to $58.2 \%$ for a single-person household. Aggregating all the households, on average more than $50 \%$ of total expenditures are spent on food. These numbers are rather high compared to estimates for other countries. For instance, according to FES data in the United Kingdom on average $20 \%$ of total expenditures are spent on food. Yu and Abler (2009) found a food budget share of $46 \%$ for rural China in 2003. The 
difference of the numbers may be due to biases toward low income households in the data set. In all three years the budget share spent on food by a family with four members are smaller than by a family with five, six or more members, a result that has been also found by Haque (2005) for Australia. This may be explained by family composition, i.e. large families do not only consist of parents and children, but also of other adult family members who, of course, need more calories and therefore more food than children.

\begin{tabular}{rrrr} 
& \multicolumn{3}{c}{ Food budget shares } \\
Family size & $\mathbf{2 0 0 0}$ & $\mathbf{2 0 0 1}$ & $\mathbf{2 0 0 2}$ \\
\hline 1 & 63.6 & 60.1 & 58.2 \\
2 & 57.3 & 54.2 & 51.8 \\
3 & 51.3 & 48.2 & 47.1 \\
4 & 50.9 & 48.3 & 45.3 \\
5 & 54.4 & 50.4 & 49.3 \\
$\geq 6$ & 52.6 & 53.6 & 51.2 \\
\hline all & 54.8 & 52.6 & 50.7
\end{tabular}

Table 1: Food budget shares in Russia, 2000-2002

We now turn to the composition of food expenditures in terms of different categories. Table 2 shows the budget shares spent on total food and different food categories in 2002 ${ }^{4}$ The findings are in line with our expectations about the food consumption pattern in different income groups. Total expenditures have been separated into ten quantiles. The last column shows expenditure shares for total food. The bottom decile of households spent $63 \%$ of total expenditure on food while the top decile spent only $34 \%$. This is still more than the average household in industrialized countries spends on food (see for comparison e.g. Haque 2005, Cortez and Senauer 1996, Huang and Lin 2000), but the difference between the bottom and the top decile may be interpreted as an indicator of the distribution of income and the resulting wealth in Russia. Concerning the different food categories, the largest difference within a food category can be found in the expenditure relative to total food expenditure for bread (that includes also pasta and grains, but no potatoes), meat, and eating out (food consumption away from home). Households in the bottom decile spent $13 \%$ of total food expenditure on meat, $31 \%$ on bread, and $2 \%$ on eating out, respectively. Households in the top decile spent $24 \%$ on meat, $13 \%$ on eating out and only $7 \%$ on bread, respectively. These results imply that richer households consume fewer calories from staples and more calories from meat and meat products and eating out, i.e. we observe satiation for staples in richer households. For all other categories we find only small differences, and for beverages, milk products, sweets and fruits the expenditure shares are nearly the same. The expenditure share seems to be independent from the respective total expenditure quantile. This is probably due to the fact that some of these products play an important role in the Russian diet.

Moreover, the share spent on vegetables is increasing for higher total expenditure quan-

\footnotetext{
${ }^{4}$ The composition of the categories is described in the Appendix. Shares of food expenditure do not have to add up to one because the total expenditure category includes alcoholic drinks and tobacco, which we do not present here.
} 
Food Categories

\begin{tabular}{|c|c|c|c|c|c|c|c|c|c|c|c|}
\hline \multirow[b]{2}{*}{ Deciles } & \multicolumn{10}{|c|}{ Food Categories } & \multirow[b]{2}{*}{ Total food } \\
\hline & Meat & Bread & Sweets & Vegetables & Fruits & Milk & Oil & Beverages & Fish & Eating Out & \\
\hline \multirow[t]{2}{*}{$1 \mathrm{st}$} & 0.09 & 0.18 & 0.05 & 0.03 & 0.02 & 0.07 & 0.06 & 0.03 & 0.02 & 0.01 & \multirow{2}{*}{0.63} \\
\hline & $(0.13)$ & $(0.31)$ & $(0.07)$ & $(0.05)$ & $(0.03)$ & $(0.11)$ & $(0.10)$ & $(0.05)$ & $(0.03)$ & $(0.02)$ & \\
\hline \multirow[t]{2}{*}{ 2nd } & 0.13 & 0.12 & 0.04 & 0.04 & 0.02 & 0.07 & 0.05 & 0.02 & 0.02 & 0.02 & \multirow[t]{2}{*}{0.61} \\
\hline & $(0.20)$ & $(0.22)$ & $(0.07)$ & $(0.06)$ & $(0.03)$ & $(0.11)$ & (0.09) & $(0.04)$ & $(0.03)$ & (0.04) & \\
\hline \multirow[t]{2}{*}{ 3rd } & 0.15 & 0.10 & 0.04 & 0.04 & 0.02 & 0.06 & 0.05 & 0.02 & 0.02 & 0.02 & \multirow[t]{2}{*}{0.60} \\
\hline & $(0.23)$ & $(0.18)$ & $(0.07)$ & $(0.06)$ & $(0.04)$ & $(0.10)$ & $(0.08)$ & $(0.04)$ & $(0.03)$ & $(0.05)$ & \\
\hline \multirow[t]{2}{*}{ 4th } & 0.13 & 0.08 & 0.03 & 0.05 & 0.02 & 0.06 & 0.04 & 0.02 & 0.02 & 0.04 & \multirow[t]{2}{*}{0.55} \\
\hline & $(0.22)$ & $(0.17)$ & $(0.06)$ & $(0.07)$ & $(0.04)$ & $(0.10)$ & $(0.07)$ & $(0.04)$ & $(0.03)$ & $(0.07)$ & \\
\hline \multirow[t]{2}{*}{5 th } & 0.14 & 0.07 & 0.03 & 0.04 & 0.02 & 0.05 & 0.03 & 0.02 & 0.01 & 0.04 & \multirow[t]{2}{*}{0.54} \\
\hline & $(0.24)$ & $(0.14)$ & $(0.06)$ & $(0.07)$ & $(0.05)$ & $(0.10)$ & $(0.06)$ & $(0.04)$ & $(0.03)$ & (0.08) & \\
\hline \multirow[t]{2}{*}{ 6th } & 0.13 & 0.06 & 0.03 & 0.04 & 0.03 & 0.05 & 0.03 & 0.02 & 0.01 & 0.04 & \multirow[t]{2}{*}{0.51} \\
\hline & $(0.25)$ & $(0.14)$ & $(0.07)$ & $(0.07)$ & $(0.05)$ & (0.09) & $(0.06)$ & $(0.04)$ & $(0.03)$ & $(0.08)$ & \\
\hline \multirow[t]{2}{*}{ 7th } & 0.12 & 0.05 & 0.03 & 0.03 & 0.03 & 0.04 & 0.03 & 0.02 & 0.01 & 0.05 & \multirow[t]{2}{*}{0.48} \\
\hline & $(0.24)$ & $(0.12)$ & (0.07) & $(0.06)$ & $(0.05)$ & (0.09) & $(0.06)$ & $(0.04)$ & $(0.03)$ & (0.10) & \\
\hline \multirow[t]{2}{*}{ 8th } & 0.12 & 0.04 & 0.03 & 0.04 & 0.02 & 0.04 & 0.02 & 0.02 & 0.01 & 0.05 & \multirow[t]{2}{*}{0.46} \\
\hline & $(0.25)$ & $(0.10)$ & $(0.06)$ & $(0.07)$ & $(0.05)$ & (0.09) & $(0.05)$ & $(0.04)$ & $(0.03)$ & (0.10) & \\
\hline \multirow[t]{2}{*}{ 9th } & 0.10 & 0.03 & 0.03 & 0.04 & 0.02 & 0.03 & 0.02 & 0.02 & 0.01 & 0.06 & \multirow[t]{2}{*}{0.43} \\
\hline & $(0.25)$ & $(0.09)$ & $(0.06)$ & $(0.08)$ & $(0.05)$ & $(0.08)$ & $(0.04)$ & $(0.05)$ & $(0.03)$ & $(0.12)$ & \\
\hline \multirow[t]{2}{*}{ 10th } & 0.08 & 0.02 & 0.02 & 0.03 & 0.02 & 0.03 & 0.01 & 0.02 & 0.01 & 0.05 & \multirow[t]{2}{*}{0.34} \\
\hline & $(0.24)$ & $(0.07)$ & $(0.05)$ & $(0.07)$ & $(0.06)$ & $(0.09)$ & $(0.04)$ & $(0.05)$ & $(0.03)$ & $(0.13)$ & \\
\hline
\end{tabular}

Table 2: Average budget shares allocated to different sub-categories of food for each decile of total expenditure. Entries in parentheses refer to shares of total food expenditure. 
tiles. This might be due to consumption of harvested fruits and vegetables. Households may have their own garden to grow fruits and vegetables and therefore these items are not part of their grocery shopping. In our data set, about $50 \%$ of the households in all three years report that harvested food is part of their consumption. Additionally, increasing expenditures on vegetables may be due to health reasons, i.e. richer households think more about the nutritional values of their diets and the resulting health consequences than poor households. In comparison, poorer households seem to get most of their calories from staples and meat, i.e. they consume those types of food that deliver a high amount of calories. This implies that these households have to spend a large share of their total expenditures on food to meet their caloric needs, and they concentrate their consumption on foods with a high calorie density.

Looking at expenditure shares gives us a first idea of the consumption patterns. To get a more detailed picture of the diet actually consumed, we calculate calorie consumption and composition of the calorie intake in terms of macronutrients. We separate men and women because of their different needs in terms of daily calorie intake and distinguish four quantiles of total expenditures. Children until the age of 17 have been excluded from the sample. Nutrition composition is displayed for the years 2000 and 2002 only, because we did not find major changes within one year. Table 3 shows the results. We see, with one exception, that individuals with higher total expenditures have a higher calorie intake. This holds for both men and women and for both years. In all expenditure quartiles, women consume fewer calories than men but the composition of the diet appears to be similar to men's diet. At least partly this is due to the fact that food consumption patterns consist of meals shared by the whole family, i.e. all family members eat the same kind of food, but different amounts of it. Furthermore, individuals in higher quantiles consume a higher share of protein and fat in the diet, while the share of carbohydrates is lower in comparison to the lowest two quantiles. Since the Russian diet was historically dominated by carbohydrates consumption, its decreasing share may be interpreted as a satiation effect that occurs with rising total expenditures.

Additionally, differences of total calories and macronutrient intake are higher between total expenditure quantiles than between the two years. For instance, in 2000 males in the bottom quantile consumed on average $2079.3 \mathrm{kcal}$, while males in the top quantile consumed on average $2637.9 \mathrm{kcal}$. The difference between both values corresponds to the calorie content of a light meal. In contrast, the difference of calorie intake for women per day is smaller. In 2000 , females in the bottom quantile consumed on average $1517.7 \mathrm{kcal}$ per person per day and females in the top quantile consumed $1790.6 \mathrm{kcal}$ per person per day. Female calorie consumption is not only smaller than male calorie consumption, it is even relatively low in comparison to calorie consumption in industrialized countries. The calorie intake of Russian women equals the recommended amount of calorie consumption for females in industrialized countries who want to lose weight $:^{5}$

\footnotetext{
${ }^{5}$ In comparison, in 2000 US Americans consumed on average $2800 \mathrm{kcal}$ per day, while only $2200 \mathrm{kcal}$ per day are necessary to meet the energy needs of the average American (Putnam, Allshouse, and Scott Kantor 2002).
} 


\begin{tabular}{ccccccccc} 
& \multicolumn{9}{c}{2000} & & & & 2002 & \\
& Total Calories & Protein(\%) & Carbs $(\%)$ & Fat(\%) & Total Calories & Protein(\%) & Carbs(\%) & Fat(\%) \\
\hline Males & & & & & & & & \\
1st quantile & 2079.3 & 11.9 & 60.1 & 28.1 & 2178.9 & 12.4 & 57.0 & 30.5 \\
2nd quantile & 2393.6 & 12.6 & 55.8 & 31.6 & 2316.9 & 12.9 & 54.1 & 32.9 \\
3rd quantile & 2485.6 & 12.8 & 54.8 & 32.4 & 2421.9 & 13.3 & 52.4 & 34.3 \\
4th quantile & 2637.9 & 13.2 & 53.3 & 33.5 & 2519.4 & 13.6 & 50.9 & 35.5 \\
$\begin{array}{c}\text { Females } \\
\text { st quantile }\end{array}$ & 1517.7 & 11.4 & 60.9 & 27.7 & 1581.8 & 12.1 & 58.7 & 29.2 \\
2nd quantile & 1664.1 & 11.6 & 58.7 & 29.7 & 1721.8 & 12.2 & 55.7 & 32.1 \\
3rd quantile & 1714.1 & 12.0 & 56.6 & 31.4 & 1728.1 & 12.6 & 53.5 & 33.1 \\
4th quantile & 1790.6 & 12.6 & 54.4 & 33.0 & 1554.7 & 13.1 & 51.7 & 35.2 \\
\hline
\end{tabular}

Table 3: Nutrition composition and total calorie consumption per person per day, 2000 and 2002. Sample included 3517 men and 4784 women in 2000 and 4049 men and 5558 women in 2002 


\section{Estimation of quantity vs. quality changes}

Having observed that, as income increases, households consume more calories and relatively less carbohydrates, we now analyze whether they are willing to buy more expensive food. Our aim is to disentangle the income effect on quality from the income effect on quantity. For this purpose we show that income elasticity for expenditure can be decomposed as the sum of income elasticity for quantity and income elasticity for quality. Three different Engel curves correspond to the three elasticities: expenditure, quantity and quality Engel curves.

\subsection{Elasticity decomposition}

Income elasticity for expenditure is the common tool for measuring the responsiveness of a particular expenditure (e.g. on food) to changes in income. ${ }^{6}$ It is formally defined as

$$
\eta=\frac{d y}{y} \cdot \frac{x}{d x}
$$

where $y$ is expenditure on a particular good and $x$ is total expenditure. Since $y=p \cdot q$, where $p$ is the unit price of the good and $q$ is the quantity demanded, we obtain the following decomposition:

$$
\eta=\frac{d(p \cdot q)}{p \cdot q} \cdot \frac{x}{d x}=\left[\frac{(d p) q}{p q}+\frac{(d q) p}{p q}\right] \frac{x}{d x}=\left[\frac{d p}{p}+\frac{d q}{q}\right] \frac{x}{d x}=\delta+\sigma,
$$

where $\delta$ and $\sigma$ are the total expenditure elasticities for quality and quantity respectively.

This implies that the income elasticity for expenditure is simply the sum of the income elasticity for quality and the income elasticity for quantity. In empirical estimation the elasticities for quality and quantity will never add up exactly to elasticity for expenditure, because of the inevitable presence of error terms. Therefore, we can only assume that $\hat{\eta}_{\text {exp }} \approx \hat{\delta}_{p}+\hat{\sigma}_{q}$.

Engel curves are the standard method to estimate income elasticities, since there is a close relationship between the derivative of an Engel curve and income elasticity. Following Bils and Klenow (2001), we define here three types of Engel curves. Expenditure Engel curves trace out expenditure on a commodity against total expenditure (proxy for permanent income). In this case the general functional form is

$$
y_{i}^{g}=f_{y}\left(x_{i}\right)+\varepsilon_{i}, \quad y_{i}^{g} \equiv p_{i}^{g} \cdot q_{i}^{g},
$$

where $y_{i}^{g}$ is the expenditure allocated by household $i$ to a category of commodities $g$, and $x_{i}$, $p_{i}^{g}$, and $q_{i}^{g}$ are total expenditure, unit price and quantity respectively.

\footnotetext{
${ }^{6}$ When income is proxied by total expenditure it is called total expenditure elasticity.
} 
Quantity Engel curves describe the functional dependence of quantity demanded on total expenditure:

$$
q_{i}^{g}=f_{q}\left(x_{i}\right)+\varepsilon_{i},
$$

where $q_{i}^{g}$ is the quantity that household $i$ consumed of good $g$.

Finally, in the case of quality Engel curves the dependent variable is the unit price that a household is willing to pay for one unit of commodity $g$ :

$$
p_{i}^{g}=f_{p}\left(x_{i}\right)+\varepsilon_{i},
$$

where in this case $p_{i}^{g}$ is the unit price that household $i$ is paying for $g$.

Notice that from equations (1) and (2) elasticities can be written as

$$
\eta=\frac{d \log y}{d \log x}, \quad \sigma=\frac{d \log q}{d \log x}, \quad \delta=\frac{d \log p}{d \log x} .
$$

Hence if the variables entering in any of the Engel curves defined above are taken in logarithms, the derivative of this Engel curve is equal to the elasticity.

In order to estimate these types of Engel curves and the corresponding elasticities, we need an adequate unit of measurement for food consumption. Our proposed unit is number of calories consumed. Alternative units such as kilograms or liters may be adequate to describe purchasing decisions and exchanges on the market, but they are not suitable to measure the physiological aspect of food consumption, which aims at satisfying the need for nutrition. Whether a level of satiation is reached depends ultimately on the number of calories consumed, which of course varies among individuals. For this reason calorie intake is a suitable unit of reference to measure quantity of food consumption.

Correspondingly, our measure for food quality is price per calorie.7 This allows us to compare different types of food on a common basis. Some goods are cheap and high in calories and some goods are expensive and are low in calories. If households substitute the latter for the former when income rises, one should expect to observe income elasticity of food expenditure greater than income elasticity of quantity 8

To account for differences in household size and composition, we apply equivalence scales to weight both food expenditures and total expenditures. Equivalence scales are used to compare the resources of households and simultaneously account for differences in household size and composition. Households may have economies of scale, because household members are assumed to share their resources. Examples are housing and electricity usage (Deaton and Muellbauer 1980). Additionally, as it is almost impossible to draw conclusions from household data on individual consumption, the household has to be treated as an unit and therefore

\footnotetext{
${ }^{7}$ Strictly speaking our measure is expenditure per calorie consumed.

${ }^{8}$ The substitution of staples for other kinds of food is even observable when the new composition of the diet is worse from a nutritional point of view, because individuals might get not enough calories or less vitamins (Jensen and Miller 2008).
} 
the composition of the household is an important factor $9^{9}$ By applying equivalence scales each household type is assigned a value in proportion to its needs. Factors taken into account are commonly size of the household and age of its members, to distinguish between adults and children. For our analysis we used the OECD-modified equivalence scale that was first proposed by Hagenaars, de Vos, and Zaidi (1994), which assigns a value of 1 to the household head, of 0.5 to each additional adult member and of 0.3 to each child.

\subsection{Nonparametric elasticity estimates}

In the standard parametric approach income elasticities are obtained by specifying a functional form $f(x)$ of the Engel curve and taking $d(\log f(x)) / d(\log x)$. For example, if the Engel curve is $\log y=\beta \log x+\varepsilon$, the income elasticity turns out to be simply the parameter $\beta$. Yet, a functional form for the Engel curve is difficult to justify both from a theoretical and empirical point of view. Therefore we estimate elasticities using a nonparametric approach in which we do not specify a functional form for $f(x)$. We are still able to obtain the average derivative of the Engel curve, where the variables have to enter in logarithms, in order to get elasticities. The average derivative of a nonparametric regression function is estimated by applying the method proposed by Härdle and Stoker (1989) ${ }^{10}$ We start from an Engel curve in the following general form:

$$
\log (y)=m(\log x)+\varepsilon
$$

where $y$ is either expenditure on food, or calories, or price per calorie, depending on which of the three elasticities we are estimating (we drop household and commodity indices for convenience), $x$ is total expenditure, and $m(\log x) \equiv E(y \mid \log x)$ is the unknown regression function. We are interested in estimating the average derivative

$$
\delta=E\left(m^{\prime}(\log x)\right)
$$

where $m^{\prime} \equiv D[m(\log x)]$ is the derivative with respect to $\log x$ and the expected value $E$ is taken with respect to the marginal distribution of $\log x$. The estimate proposed by Härdle and Stoker (1989) is

$$
\hat{\delta}=-\frac{1}{T} \sum_{t=1}^{T} y_{t} \frac{\widehat{D f_{h}}\left(x_{t}\right)}{\widehat{f}_{h}\left(x_{t}\right)} I\left\{\widehat{f}_{h}\left(x_{t}\right)>b_{T}\right\},
$$

where $\widehat{f}_{h}\left(x_{t}\right)$ and $\widehat{D f_{h}}\left(x_{t}\right)$ are the kernel density estimates of $f(x)$ and $D[f(x)]$ respectively, with a bandwidth $h$. Moreover, $I\{\cdot\}$ is the indicator function, and $b_{T}$ is a trimming

\footnotetext{
${ }^{9}$ These assumptions imply the negation of intra-household inequality. For a discussion on this topic see Haddad and Kanbur (1990).

${ }^{10}$ For a recent discussion about average derivative method see Banerjee (2007).
} 
bound which converges to zero. In our application we set the bound to drop the $\alpha=5 \%$ of observations with smallest estimated density values.

Table 4 shows the estimates of the average derivatives for all three types of elasticities for the years 2000, 2001, and 2002 and for urban, rural and PGT areas. Standard errors are obtained via bootstrap (Efron and Tibshirani 1993). The results confirm to a good extent the theoretical decomposition of elasticities proposed in equation (1). Indeed quantity and quality elasticities approximately add up to expenditure elasticities. The residual, calculated as $(\hat{\delta}+\hat{\sigma})-\hat{\eta}$, is displayed in the last row of table 4 . Notice that the residual is of a magnitude comparable to that of the standard errors from the different elasticity estimates, with exception of urban areas. We do not, however, have any explanation of the fact that the residuals are positive in all the cases.

We want to test (i) whether the obtained elasticities are significantly positive, (ii) to what extent they differ across types of areas, and (iii) if there are significant changes across time. For this purpose we apply a series of Wald tests. In the first set of tests, the hypothesis of zero elasticity is strongly rejected for the expenditure, quality and quantity cases. In the upper part of table 5 we present only the results for quality elasticities $\hat{\delta}$, in which we obtain high values in the Wald statistic. The results confirm that as households become richer they expand expenditures on average both in quantity and quality.

In a second battery of tests, we formulate the hypotheses that income elasticity for quality does not change across years within area type. The second part of table 5 reports the results. Significant differences are found only in rural areas both between 2000-2001 and between 2001-2002.

In a third series of tests (third part of table 5), the null hypothesis is that income elasticities for quality are equal across areas for each year. In 2002 the hypotheses are not rejected for all the areas, i.e. all three estimated quality elasticities are not significantly different from each other. In contrast, in 2000 and 2001 significant similarities are found between rural and PGT areas and between urban and PGT areas respectively. These results may indicate a tendency of economic convergence between different areas.

In a fourth battery of tests, presented in the lower part of table 5, we check whether elasticities for quantity Engel curves $\hat{\delta}$ are similar to elasticities for quality Engel curves $\hat{\sigma}$. Since our estimation results show in all cases larger quality elasticities than quantity elasticities it is important to know whether quality elasticities are significantly larger than quantity elasticities. For that reason we test for the equality of $\hat{\delta}$ and $\hat{\sigma}$. The hypotheses is always rejected, except for $\hat{\delta}$ and $\hat{\sigma}$ in 2001 for rural areas. In other words, quantity elasticities and quality elasticities are always different among each other, with the single exception mentioned. As we observe larger values for quality elasticities this suggests that the responsiveness of quality to changes in total expenditures is greater than the responsiveness of quantity to the same changes in total expenditure.

To what extent is the quality responsiveness greater than the quantity responsiveness? The penultimate row of table 4 presents the size of the quality elasticity relative to the sum of responses in quality and quantity. In every case the ratio is higher than $50 \%$ implying a higher 


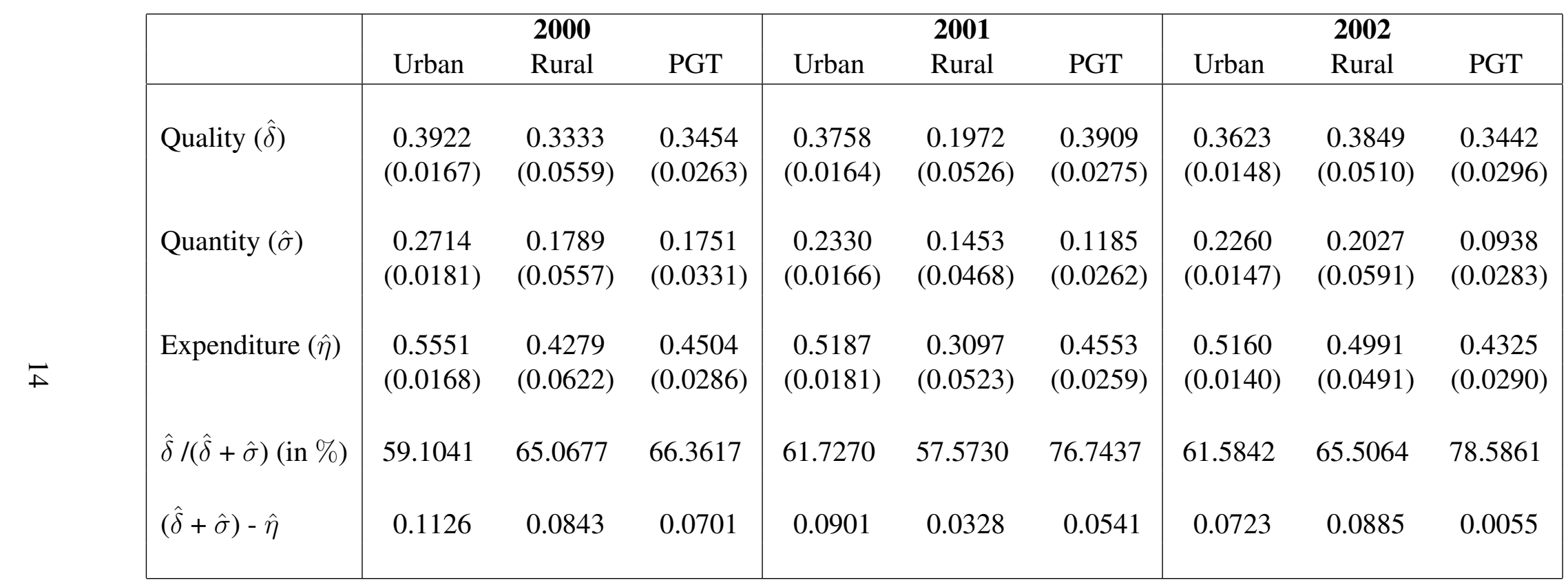

Table 4: Elasticities for quality, quantity, and expenditure Engel curves. Ratio of the estimated quality elasticities to the sum of quality and quantity elasticities in per cent. The last row displays the residuum of the estimated elasticity decomposition. Standard errors in parentheses. 
effect of quality on calorie consumption in comparison to the effect of quantity of calorie consumption. While for urban areas the ratio almost stays the same, the ratio for PGT areas is increasing. We find evidence that quality consideration have an effect on food consumption patterns and this effect is stronger than the effect of quantity.

The estimated elasticities show the response of quality and quantity on income changes as an average over all households. To display the effects of increasing income in more detail, we estimate expenditure, quantity, and quality Engel curves as described in equations (3) (5). Engel curves are estimated on the basis of a nonparametric approach, since we do not want to impose any functional form on the data (see Engel and Kneip (1996) for a discussion). We apply the Kernel regression estimator proposed by Naradaya (1964) and Watson (1964), choosing a Gaussian Kernel and an optimal bandwidth via cross-validation (see Bowman and Azzalini (1997)). Confidence intervals are calculated using a bootstrap procedure (Efron and Tibshirani 1993). We first estimate expenditure Engel curves for 2000, 2001, and 2002, for urban, rural, and PGT areas.

Figure 1 shows the resulting graphs for expenditure Engel curves. These diagrams display the typical shape of the food Engel curve, which is quite rapidly increasing for low levels of total expenditure and slowing down for higher levels of total expenditure. The negative slope of some of the Engel curves at the highest levels of total expenditure should be taken with caution because of the scarcity of observation in this interval, where indeed we observe diverging confidence bonds. Sample sizes range from 2152 to 2865 for urban area, from 215 to 233 for rural area, and from 936 to 1049 for PGT area.

Figure 2 displays the results for quantity Engel curves. Years and regions are the same. In these diagrams ordinates measure household's calorie intake per week. Shapes are remarkable more flat than those observed for expenditure ECs (figure1). This already indicates a major role played by quality. Notice that in rural areas curves are steeper than in other areas. We address this difference more fully below.

Quality Engel curves are reproduced in figure 3, wherein $y$-axes measure price per calorie in current year rubles. Shapes are notably similar to the respective expenditure ECs. This confirms the remark we have just made about the role of quality.11

Looking in detail at figure 3, in 2000 all the curves start with a positive slope. This implies that as households get richer they pay a higher price per calorie. The average unit price households are paying does not much vary among the three types of areas, as confirmed by the range of the $y$-axis in the first three diagrams of figure 3. Slopes tend to decrease as total expenditure increases. For the urban area the slope of the Engel curve becomes even negative for high values of $x$. Since in this case both confidence bonds display a negative slope at the highest levels of income, the decrease of slope is not simply due to the fact that the number of rich families in the sample is quite small. Instead it indicates, at least for this sample, the presence of a limit in the price families are willing to pay for high quality goods (Chai and

\footnotetext{
${ }^{11}$ As mentioned in section 2 , individual calorie intake has been calculated on the basis of actual food consumption per person per day. Due to harvesting and stockpiling our calculation of the price per calorie is biased, because we cannot estimate how much calories are consumed from harvested food.
} 


\begin{tabular}{|c|c|c|}
\hline \multicolumn{3}{|c|}{ Hypothesis tests } \\
\hline Null hypothesis & Wald statistic W & $P\left(\chi_{1}^{2}>W\right)$ \\
\hline $\begin{array}{l}\delta_{U R B 00}=0 \\
\delta_{U R B 01}=0 \\
\delta_{U R B 02}=0 \\
\delta_{R U R 00}=0 \\
\delta_{R U R 01}=0 \\
\delta_{R U R 02}=0 \\
\delta_{P G T 00}=0 \\
\delta_{P G T 01}=0 \\
\delta_{P G T 02}=0\end{array}$ & $\begin{array}{r}553.45 \\
526.67 \\
599.05 \\
35.52 \\
14.08 \\
56.90 \\
171.94 \\
201.90 \\
135.23\end{array}$ & $\begin{array}{l}0.0000 \\
0.0000 \\
0.0000 \\
0.0000 \\
0.0002 \\
0.0000 \\
0.0000 \\
0.0000 \\
0.0000\end{array}$ \\
\hline $\begin{array}{l}\delta_{U R B 01}=\delta_{U R B 00} \\
\delta_{U R B 02}=\delta_{U R B 01} \\
\delta_{\text {RUR01 }}=\delta_{\text {RUR00 }} \\
\delta_{\text {RUR02 }}=\delta_{\text {RUR01 }} \\
\delta_{P G T 01}=\delta_{P G T 00} \\
\delta_{P G T 02}=\delta_{P G T 01}\end{array}$ & $\begin{array}{r}1.01 \\
0.83 \\
6.70 \\
13.53 \\
2.74 \\
2.49\end{array}$ & $\begin{array}{l}0.3147^{* * *} \\
0.3626^{* * *} \\
0.0096 \\
0.0002 \\
0.0981^{* *} \\
0.1142^{* * *}\end{array}$ \\
\hline $\begin{array}{l}\delta_{U R B 00}=\delta_{R U R 00} \\
\delta_{U R B 00}=\delta_{P G T 00} \\
\delta_{R U R 00}=\delta_{P G T 00} \\
\delta_{U R B 01}=\delta_{R U R 01} \\
\delta_{U R B 01}=\delta_{P G T 01} \\
\delta_{R U R 01}=\delta_{P G T 01} \\
\delta_{U R B 02}=\delta_{R U R 02} \\
\delta_{U R B 02}=\delta_{P G T 02} \\
\delta_{R U R 02}=\delta_{P G T 02}\end{array}$ & $\begin{array}{r}12.49 \\
7.89 \\
0.05 \\
118.92 \\
0.85 \\
13.58 \\
2.33 \\
1.50 \\
0.64\end{array}$ & $\begin{array}{l}0.0004 \\
0.0050 \\
0.8291^{* * *} \\
0.0000^{\text {* }} \\
0.3555^{* * *} \\
0.0002^{\text {}} \\
0.1266^{* * *} \\
0.2204^{* * *} \\
0.425^{* * *}\end{array}$ \\
\hline $\begin{array}{l}\delta_{U R B 00}=\sigma_{U R B 00} \\
\delta_{U R B 01}=\sigma_{U R B 01} \\
\delta_{U R B 02}=\sigma_{U R B 02} \\
\delta_{R U R 00}=\sigma_{\text {RUR00 }} \\
\delta_{\text {RUR01 }}=\sigma_{\text {RUR01 }} \\
\delta_{\text {RUR02 }}=\sigma_{\text {RUR02 }} \\
\delta_{\text {PGT00 }}=\sigma_{\text {PGT00 }} \\
\delta_{\text {PGT01 }}=\sigma_{\text {PGT01 }} \\
\delta_{\text {PGT02 }}=\sigma_{\text {PGT02 }}\end{array}$ & $\begin{array}{r}52.53 \\
76.04 \\
84.78 \\
7.62 \\
0.97 \\
12.75 \\
41.81 \\
98.07 \\
71.57\end{array}$ & $\begin{array}{l}0.0000 \\
0.0000 \\
0.0000 \\
0.0058 \\
0.3236^{* * *} \\
0.0004 \\
0.0000 \\
0.0000 \\
0.0000\end{array}$ \\
\hline
\end{tabular}

Table 5: Wald tests on different hypotheses about elasticities. $\delta \equiv$ elasticity for Quality Engel Curve, $\sigma \equiv$ elasticity for Quantity Engel Curve. 
Moneta 2008). Furthermore, due to supply shortages it may be not possible for rich households to buy food at a certain quality level. However, the shape of this curve is still a puzzle to be solved by further investigation.

\section{Conclusion}

In this paper we analyzed food consumption in Russia between 2000 and 2002. We estimated three different types of income elasticities, namely elasticity for food expenditure, quantity, and quality, and the correspondent Engel curves. Elasticities were estimated using the nonparametric method of average derivatives. We found that, as income increases, households consume not only more calories, but also pay a higher price per unit, implying that they buy higher quality food. Bils and Klenow (2001) have already found that the responsiveness of quality to income increases is stronger than the responsiveness of quantity for many nondurable goods, such as pieces of furniture, clocks, cars, and jewelery, items usually classified as luxury goods. We suggest that this phenomenon holds also for a basic commodity such as food in a middle income country. This is in contrast to the findings of Subramanian and Deaton (1996), who do not find significant differences between quality and quantity responsiveness in India.

Our results can be interpreted in the light of the evolutionary theory of consumption. Food consumption, as mentioned, is assumed to be driven not only by the need for nutrition but also by other "residual needs", such as need for status, social recognition, and other needs whose identification is not necessarily straightforward. We argue that the income elasticity for quantity captures the responsiveness of calorie intake to changes in income. Indeed copying with the need for nutrition consists ultimately and solely in consuming a certain number of calorie per day. On the other hand, because of the income elasticity decomposition presented in this paper, the influence of all the other needs on food consumption patterns is captured by quality Engel curves. Thus the responsiveness of the activities aimed at satisfying the "residual" needs can be measured by the income elasticity for quality. As income increases, people decide how to expand further their food consumption. Our empirical findings show that in this decision they are proportionally more influenced by "residual needs" than by the need for nutrition. This holds only on average and, of course, for the sample under consideration. In other words, if a family disposes of one ruble more for food consumption, this family will on average devote a higher share of this ruble to satisfy the "residual needs" than the need for nutrition.

Some of the possible shortcomings of our investigation, related to the data we use, should be mentioned here. First, supply problems in the agricultural sector may put a limit on purchasing of goods, i.e. people would like to buy more food and other kind of food but it is simply not available. This problem may occur mainly in rural areas with deteriorating infrastructure ${ }^{12}$ Second, the strong economic growth during the observed time period may have

\footnotetext{
${ }^{12}$ Due to low productivity in the agricultural sector, Russia imports several types of food, including fruits and vegetables, meat, but also canned and processed foods (OECD 2004).
} 

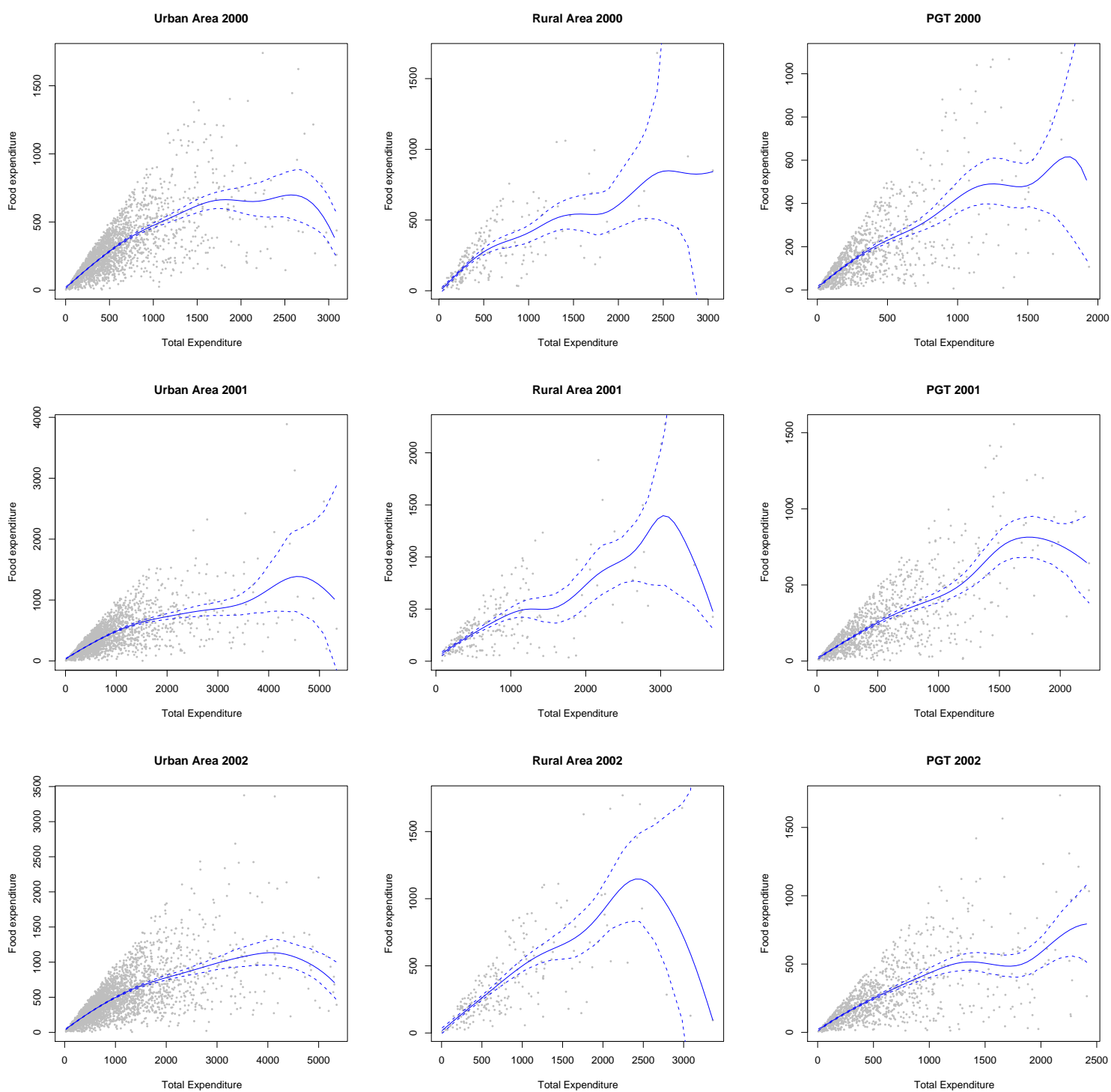

Figure 1: Food expenditure Engel curves for years 2000-2002 and for urban, rural and PGT areas. Abscissa: total expenditure per week in rubles. Ordinate: food expenditure per week in rubles. Dashed lines show confidence intervals. Each point denotes a household. 

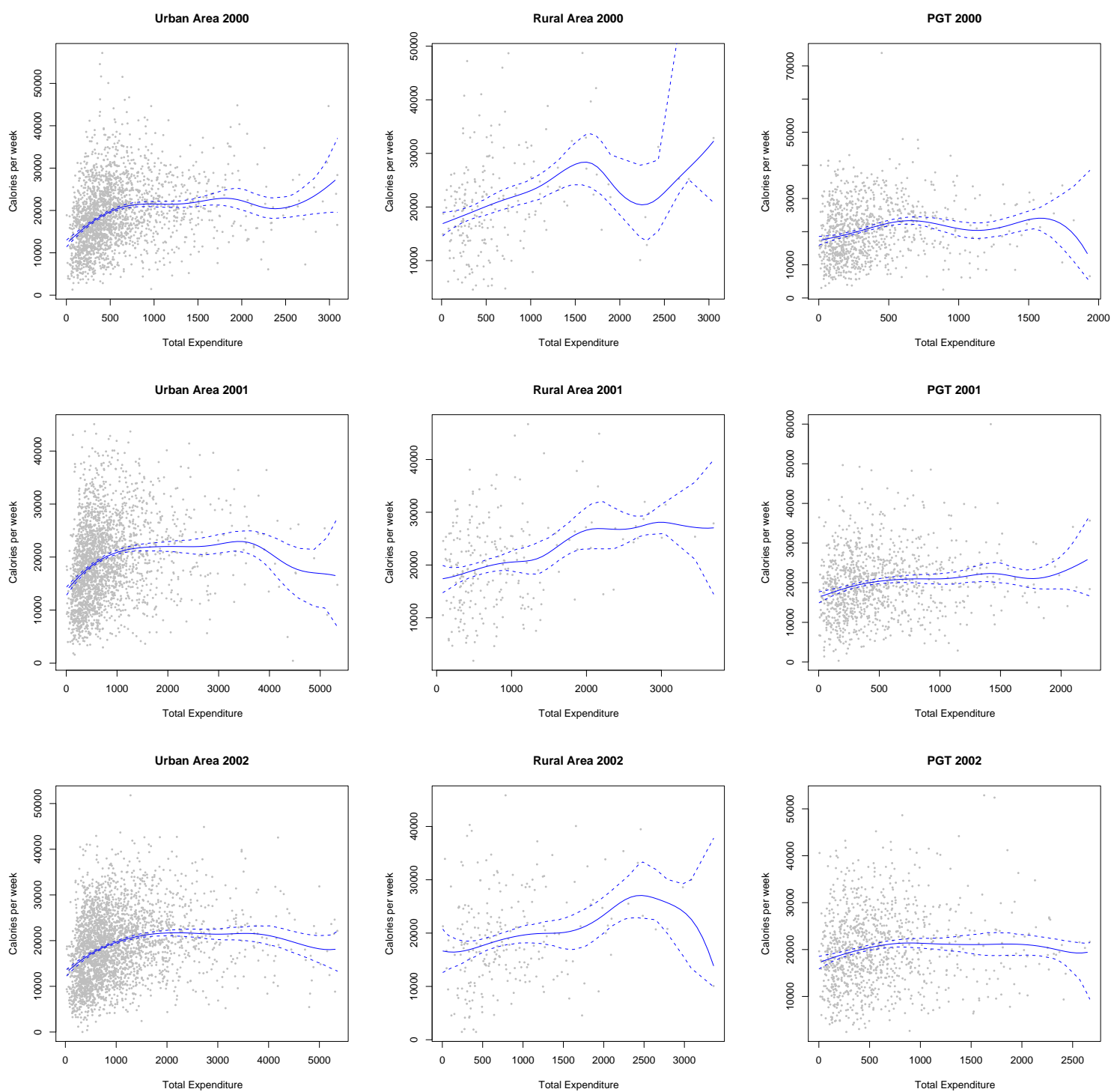

Figure 2: Quantity Engel curves for years 2000-2002 and for urban, rural and PGT areas. Abscissa: total expenditure per week in rubles. Ordinate: calories consumed per week. Dashed lines show confidence intervals. Each point denotes a household. 

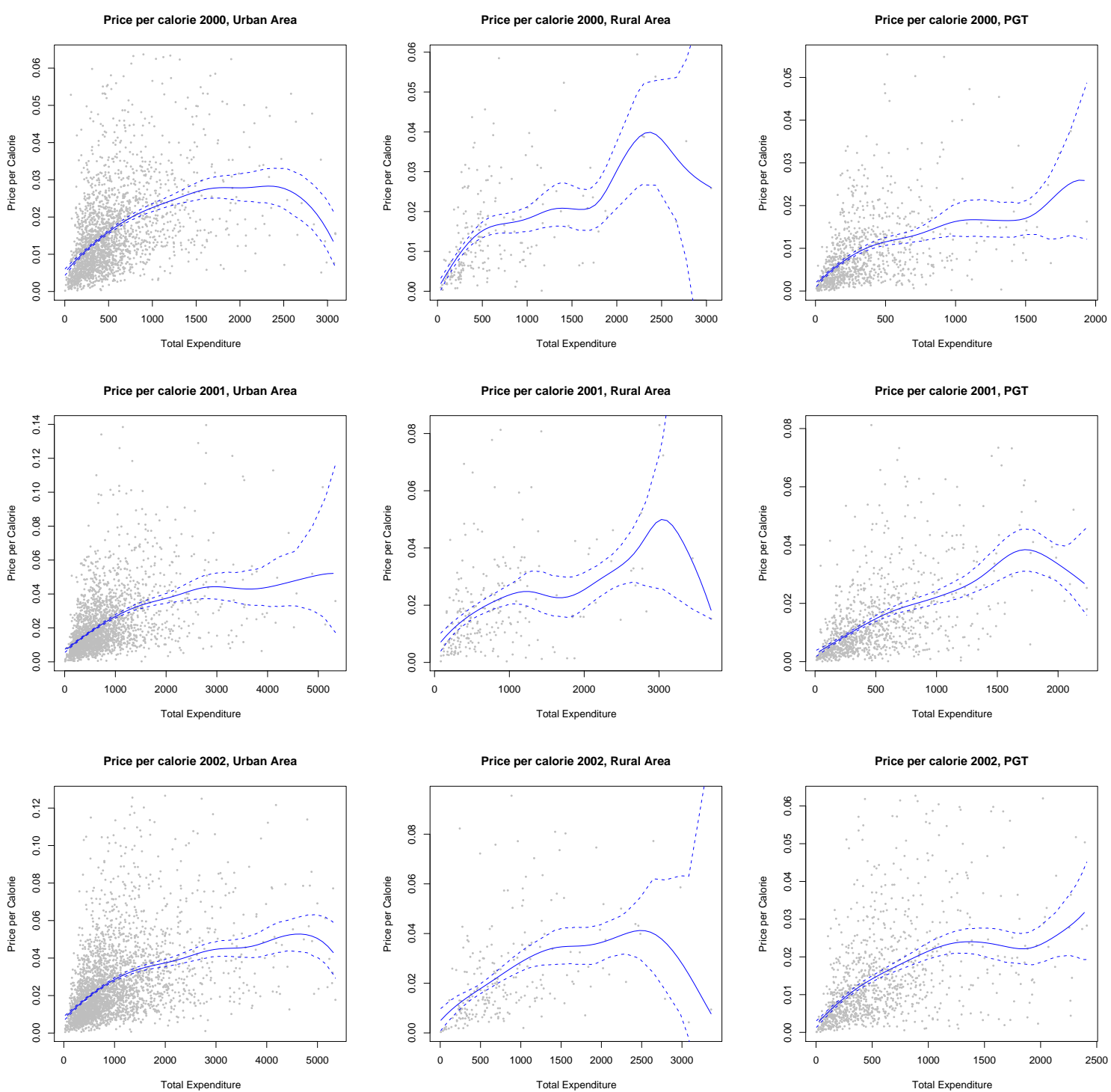

Figure 3: Quality Engel curves for years 2000-2002 and for urban, rural and PGT areas. Abscissa: total expenditure per week in rubles. Ordinate: price per calorie in rubles. Dashed lines show confidence intervals. Each point denotes a household. 
induced sharp price changes, as the inflation rates mentioned in the first section suggest. Resulting substitution effects cannot be investigated with the data available. Additionally, we cannot investigate whether rich households just pay a higher markup without getting a higher quality for the higher price paid.

Given the fact that Russia faces remarkable growth rates and consequently income is further increasing, projections on food demand should take into account the importance of quality for food choices. By relying on expenditure elasticities only, food demand in terms of quantity would be overstated and food demand in terms of quality would be understated. However, more empirical evidence from other transition or middle income countries is needed to confirm our results. 


\section{References}

BAnERJEe, A. N. (2007): "A Method of Estimating the Average Derivative," Journal of Econometrics, 136, 65-88.

Behrman, J. R., And A. B. Deolalikar (1987): "Will Developing Country Nutrition Improve with Income? A Case Study for Rural South India," Journal of Political Economy, $95,108-138$.

BILs, M., And P. J. Klenow (2001): “Quantifying Quality Growth,” American Economic Review, 91, No. 4, 1006-1030.

BoiUs, H. E. (1994): "The Effect of Income on Demand for Food in Poor Countries: Are Our Food Consumption Databases Giving Us Reliable Estimates?," Journal of Development Economics, 44, 199-226.

Bowman, A. W., And A. AzZalini (1997): Applied Smoothing Techniques for Data Analysis. Oxford Science Publications.

Chai, A., And A. Moneta (2008): "Satiation, Escaping Satiation, and Structural Change: Some Evidence from the Evolution of Engel Curves," Papers on Economics and Evolution , Max Planck Insitute of Economics, Jena.

Charles, K. K., E. Hurst, and N. Roussanov (2009): "Conspicious Consumption and Race," Quarterly Journal of Economics, 74, No. 2, 425-467.

Cortez, R., And B. Senauer (1996): "Taste Change in the Demand for Food by Demographic Groups in the United States: A Nonparametric Empirical Analysis," American Journal of Agricultural Economics, 78, No. 2, 280-289.

Deaton, A., And J. Muellbauer (1980): Economics and Consumer Behavior. Cambridge University Press.

Desai, P., And T. IDSON (2000): Work Without Wages. The MIT Press.

Efron, B., And R. J. TibShirani (1993): An Introduction to the Bootstrap. Chapman \& Hall.

ENGEL, J., AND A. KNEIP (1996): "Recent Approaches to Estimating Engel Curves," Journal of Economics, 63, 187-212.

HADDAD, L., AND R. KANBUR (1990): "How Serious is the Neglect of Intra-Household Inequality?," Economic Journal, 100, 866-881.

HagenaARs, A., K. De Vos, And M. Zaidi (1994): "Poverty Statistics in the Late 1980s: Research Based on Micro-data," Discussion paper, Office for Official Publications of the European Communities. Luxembourg. 
Haque, M. O. (2005): Income Elasticity and Economic Development. Springer.

HÄrdle, W., And T. Stoker (1989): "Investigating Smooth Multiple Regression by the Method of Average Derivatives," Journal of the American Statistical Association, 84, No. 408, 986-995.

HuANG, K. S., AND B.-H. LiN (2000): "Estimation of Food Demand and Nutrient Elasticities from Household Survey Data," United States Department of Agriculture. Economic Research Service, Technical Bulletin Number 1887.

Ivanova, L., P. Dimitrov, D. Ovchariva, J. Dellava, and D. Hoffman (2006): "Economic Transition and Household Food Consumption: A study of Bulgaria from 19852002," Economics and Biology, 4, 383-397.

Jensen, R. T., And N. H. Miller (2008): "Giffen Behavior and Subsistence Consumption," American Economic Review, 98, No. 4, 1553-1577.

KaZakova, E. (2007): "Wages in a Growing Russia," Economics of Transition, 15, No. 2, 365-392.

Lehmann, H., J. Wadsworth, and A. Acquisti (1999): "Grime and Punishment: Job Insecurity and Wage Arrears in the Russian Federation," Journal of Comparative Economics, 27, 595-617.

NARADAYA, E. (1964): “On Estimating Regression,” Theory of Probability and its Application, 9, 186-190.

OECD (2004): OECD Economic Suveys: Russian Federation. OECD-Organization for Economic Co-Operation and Development.

Putnam, J., J. Allshouse, and L. Scott Kantor (2002): "U.S. Per Capita Food Supply Trends: More Calories, Refined Carbohydrates, and Fats," Food Review, 25, No. 3, 2-15.

Shleifer, A., AND D. TeISMAn (2003): “A Normal Country,” NBER Working Paper 10057, NBER, Cambridge.

Souci, S., W. Fachmann, and H. Kraut (eds.) (1989): Food Composition and Nutrition Tables 1989/1990. Wissenschaftliche Verlagsgesellschaft Stuttgart mbH.

Strauss, J., And D. Thomas (1998): "Health, Nutrition and Economic Development," Journal of Economic Literature, 36, 766-817.

Subramanian, S., and A. Deaton (1996): "The Demand for Food and Calories," The Journal of Political Economy, 104, No. 1, 133-162.

The World BANK (2002): "Russian Economic Report, No. 3, The World Bank," .

WATson, G. (1964): “Smooth Regression Analysis," Sankhya, Ser. A., 26, 359-372. 
WITT, U. (2001): “Learning to consume," Journal of Evolutionary Economics, 11, 23-36.

Yu, X., And D. Abler (2009): “The Demand for Food Quality in Rural China," American Journal of Agricultural Economics, 91, No. 1, 57-69. 


\section{A Composition of food categories}

- Meat: Canned meat, beef/veal, lamb/goat, pork, giblets, fowl, lard/other animal fat, sausage/smoked meat, semi-prepared meat products

- Fruits: Watermelons/melons, fruit-berry preserves, fresh berries, fresh fruits, dried fruits and berries, nuts and sunflower seeds

- Vegetables: Canned vegetables (excluding pickles), cabbage (including sauerkraut), potatoes, cucumbers (including pickles), tomatoes (including pickles), beets/carrots/other roots, onions/garlic, squash/pumpkin, other vegetables, mushrooms

- Bread and cereals: White bread, black bread, rice/other cereals, flour, macaroni products

- Milk products and eggs: canned and powdered milk, fresh milk, sour milk products, sour cream, cream cheese, cheese, eggs

- Alcohol and Tobacco: Vodka, wine, beer, tobacco

- Sweets: Sugar, candy/chocolate, preserves/jam, honey, cookies, chewing gum, ice cream

- Beverages: Tea, coffee, non-alcoholic drinks, tobacco

- Fish: fresh, frozen and dried fish, canned fish

- Oil: Vegetable oil, margarine, butter 